\title{
TRAVESSIAS DA LITERATURA contemporânea de língua portuguesa
}

Maria de Lourdes Netto simões

Se, no sentido proposto, o termo 'travessias' pressupõe percurso e percurso sugere mudança (num espaço e num tempo), as mudanças, necessariamente, ocorrem num objeto. Do objeto, pretendo aqui ocupar-me da literatura em Língua Portuguesa, no tempo contemporâneo e em seus vários espaços; fazer observações, reflexões e questionamentos sobre tendências e sinalizações dessa produção literária (alguns exemplos), visando a contribuir para a idéia em foco: 'travessia'. A intenção é, assim, abordar, nos contextos de expressões culturais em Língua Portuguesa, rotas (os caminhos expressionais) e imagens, ligadas às questões dos seus respectivos imaginários. A pretensão é de que a idéia de 'travessia' se faça visando a apontar a diversidade existente nas várias literaturas dessa mesma Língua.

Ao ocupar-me de aspectos histórico-culturais, tematizados na ficção contemporânea das várias Literaturas em Língua Portuguesa, concentrar-me-ei nas questões suscitadas pelas condições de ex-colonizador/ ex-colonizados dos seus falantes, sinalizando rotas e imagens, respectivamente, em relação à produção literária de Portugal/ Brasil, Angola, Moçambique e Cabo Verde. Na sequência desse raciocínio, pelo caráter multicultural para onde tal proposta aponta, considero pertinente esclarecer o meu entendimento de cultura. 
Para essas considerações, tomo cultura não na visão clássica (herança de tradições, e costumes), mas na perspectiva ampla, que não esbarra na história, mas se alimenta também das vivências; melhor dizendo, que acrescenta vivências à herança, isto significando "criatividade humana em ação" (Erikson, 1997: 33). Nesse raciocínio, pensar cultura provoca pensar a identidade cultural, composta de múltiplas camadas e entendida "como um senso de pertinência que é moldado pela intersecção de múltiplas influências" (Kindler, 1997: 22). Pelo processo relacional da identidade cultural, impõem-se as perguntas: quem somos, com quem nos relacionamos?

Tomo, de Homi Bhabha, a concepção de entre-lugar, para situar o quê considero o foco dessas discussões, ou seja, os "momentos ou processos que são produzidos na articulação de diferenças culturais" (Bhabha: 1998, 20).

Consideradas as diferenças histórico-culturais dos povos lusófonos (e não vou discutir aqui o sentido 'colonizador' que o termo lusófono suscita), existem pontos de relação entre os textos africanos, brasileiros, asiáticos e portugueses?. Em se tratando de questões do imaginário, além das perspectivas de ex-colonizados, ex-colonizador, questões míticas, simbólicas ou mesmo identitárias, que perpassam essas literaturas, sugerem 'pontes' lusófonas? Se consideramos que a história alimenta a ficção e essa, por sua vez, influencia a história (Simões: 1998: 23), temos de considerar as condições históricas e culturais diversas dos povos de Língua Portuguesa e, por conseguinte, das suas respectivas literaturas. Que 'travessias' podem ser apontadas nessas literaturas?

1 - Dentro do foco proposto, um primeiro aspecto a ser abordado é o das "descobertas" portuguesas. Sobre o tema, ou suscitados pelas viagens portuguesas, tem destaque uma profusão de textos que tratam principalmente de questões identitárias. Em Portugal, dentre outros, Lobo Antunes, ao escrever As Naus (1988), fala de viagens e conquistas portuguesas. Retoma os personagens históricos de Os Lusíadas e, intertextualizando a obra de Camões, revê ironicamente a história. Tomando o regresso das caravelas do poeta luso, faz dele o regresso dos retornados das antigas colônias portuguesas. Em O Conquistador (1990), Almeida Faria busca, também, discutir o português e a sua identidade. Concebe o personagem Sebastião que, por seu lado paródico, dessacraliza o mito nacional - o rei D. Sebastião. Ambos fazem da história "ponte" para refletir uma situação do presente de Portugal; refletir um país despossuído e, por isso mesmo, também, um povo em revisão da sua própria identidade.

Sobre esse mesmo foco das viagens portuguesas, na intersecção Brasil/ Portugal, hoje, impõem-se os 500 anos (descoberta/ achamento) do Brasil pelos portugue-

Légua \& meia: Revista dr litrpatura \& Divirsidadr Cultural -115 
ses. Bem de acordo com tal contexto, recentes experiências recorrem a linguagens diversas - cinematográfica, musical, pictórica, ficcional, em quadrinhos -, construindo discursos próprios ou somando-se, complementando-se em reinterpretação dos textos fundadores da nação Brasil; dentre todos, notadamente a Carta de Pero Vaz de Caminha.

No curso dessa temática, entre a história e a ficção, a tendência de expressão jornalística tem no brasileiro Eduardo Bueno um exemplo com três bem sucedidos livros publicados: A Viagem do Descobrimento (1998), Náufragos, Traficantes e Degredados (1998), Capitães do Brasil (1999).

Ainda dentro do tema descobrimento do Brasil, no que se refere às experiências mais recentes de quadrinização, destaco o trabalho dos portugueses José Pires e Nuno Calado: Pedro Alvares Cabral: Ventos de Glória, Marés de Infortúnio (1998) e a publicação inovadora e original dos brasileiros Henrique Campos Simões e Reinaldo Gonzaga: $O$ Achamento do Brasil - A Carta de Pero Vaz de Caminha a El-Rei D. Manuel (1999). Nessas novas propostas, interessa a comunicabilidade dos textos e é fundamental a observação da ideologia posta na fala dos personagens históricos, reconfigurados. São perspectivas que, resgatando a ambiência e a cultura da época, provocam a reflexão sobre fatos e perfis, perpassados ao longo do tempo pela fala oficial. Os códigos ideológicos, morais e gestuais das histórias em quadrinhos, sinalizadas pelos respectivos historiadores, e asseguradas pela arte dos seus desenhistas no ambiente gráfico, traduzem o comportamento de portugueses e índios e, consequentemente, as culturas branca e indígena. Naturalmente, são óticas diferenciadas: a do ex-colonizador português e a do ex-colonizado brasileiro. A primeira, admite a cobiça do governo português e assegura a boa índole do povo; ressalta portugueses bons e, outros, cobiçosos a serviço da coroa. A segunda, aponta a cobiça do colonizador, o seu desrespeito à cultura indígena, e busca conduzir o leitor a uma reflexão sobre cidadania. Se a História traz em si a aventura, e essa é elemento inerente da $\mathrm{HQ}$, as recentes experiências referidas primam por terem sabido aliar as informações histórias a uma narração instigante, onde é evidente a intenção autoral da discussão e reflexão ideológica. Então, para além dos recursos dos quadrinhos, a ideologia que subjaz, garante a reflexão crítica.

Ainda sobre o mesmo aspecto, vale mencionar $O$ Auto do Descobrimento - o romanceiro de vagas descobertas, de Jorge de Souza Araújo (1997) que, ao tempo em que canta a chegada dos portugueses às terras do Brasil, clama ao povo brasileiro a reflexão sobre a sua brasilidade. O cenário é o litoral de Porto Seguro, local da chegada da esquadra cabralina em 1500. Num primeiro plano, os atores são os portugueses e os índios. Mas são 
também os negros, pois o texto se projeta até à colonização e às capitanias hereditárias, enfocando tempos por vir em relação do presente histórico. Dessa sorte, não se limita somente à reflexão sobre a chegada de Cabral, como pode parecer à primeira vista, mas aos vários descobrimentos do Brasil: pelos indígenas (os primeiros), pelos portugueses, pelos negros; ultrapassa, dessa forma, o mero fato histórico, para uma abrangência sócio-cultural, inclusive de construção da identidade brasileira.

2 - Um outro aspecto, dentro do foco proposto (ex-colonizador/ ex-colonizados), amplia a relação para Portugal/ Brasil e África e concentra-se na libertação dos países africanos. Como todos lembramos, a revolução portuguesa do 25 de Abril de 1974 libertou os países africanos de Língua Portuguesa e teve repercussões também no Brasil (naquela época no auge do ditadura de 64), já que para aqui vieram muitos refugiados portugueses. O processo, que teve início nos anos sessenta (com as conturbações provocadas pela guerra colonial, pelo movimento estudantil, pelas questões agrárias, problemas com a censura, a repressão, a condição das mulheres na sociedade), alcançou o seu momento de eclosão na revolução dos Cravos (dos Capitães de Abril), comemorado em 1999.

A Revolução dos Cravos é, então, considerada ano marco, a partir de quando a expressão de Língua Portuguesa tomou rumos marcados. Portugal, por afinal livrar-se de 46 anos de ditadura, pôde dar vazão à sua voz sufocada; os países africanos, libertados, independentes, na condição de ex-colonizados, exprimem um imaginário que, embora povoado de lembranças e influências brancas, traduz costumes negros.

Bem a propósito é que, dentre outras publicações alusivas à data, vejo a coleção Caminhos de Abril (1999), lançada pela Editora Caminho, em comemoração ao $25^{\circ}$ aniversário dos Cravos de Abril. Apresenta onze títulos, dez ficcionais e um álbum fotográfico. Os autores que integram a coleção são oito portugueses (Alexandre Pinheiro Torres, Alice Vieira, Almeida Faria, Carlos Brito, Manuel Alegre, Maria Isabel Barreno, Mário de Carvalho e Urbano Tavares Rodrigues), dois africanos (o caboverdiano Germano Almeida e o moçambicano Mia Couto) e um brasileiro (Sebastião Salgado). São, todos eles, escritores que vivenciaram o processo revolucionário - portugueses ou filhos das ex-colônias.

Apegados à memória do vivenciado, esses autores, que revisitaram o 25 de Abril vinte e cinco anos depois, escreveram os seus textos com um objetivo comum: em referência ao tempo anteriormente vivido, fazer ver aos mais novos a importância da revolução. Para isso, uns voltam-se ao passado e, por outros focos temáticos, relembram aquela época (Alexandre Pinheiro Torres); ou aprofundam personagens

Légua \& meia: Revista dr litrpatura \& Divirsidadr Cultural -117 
antes referidas e retomadas (Almeida Faria) ou, ainda, lembram experiências vivenciadas no tempo da ditadura, como: a situação de submissão das mulheres (Isabel Barreno), ou prisão (Manuel Alegre) e fuga, às vezes acontecida na culminância do dia tão esperado (Carlos Brito, Mário de Carvalho). Outros, prendem-se ao espanto da liberdade dos primeiros momentos do 25 de Abril (Urbano Tavares). Os africanos apresentam a visão e o sentimento do ex-colonizado (Germano Almeida, Mia Couto) em lembrança do dia $\mathrm{D}$ e do que esse representou para o seu país; a certeza de que por si só ele não bastou porque a descolonização foi outro processo. $\mathrm{O}$ brasileiro apresenta tomadas fotográficas daqueles tempos. Finalmente, fazendo um percurso dos vários momentos do processo, Alice Vieira concebe várias vozes, vivendo o agora; vozes que retomam o 25 de Abril, enfatizando os ganhos que trouxe à vida quotidiana, em relação à liberdade e aos costumes .

Esses textos produzidos em 1999, respeitadas as suas diferenças autorais, têm em comum a contenção, a clareza da linguagem, o humor implícito ou explicitado, a ironia leve. A leveza da linguagem para a abordagem de temas tão graves; a rapidez garantida na economia dos adjetivos, na contenção do relato, e no tempo circunscrito; o foco assumido de forma direta. Esses expedientes, certamente, são a chave para conquistar os leitores desses tempos de comunicação tecnológica.

3 - Se, antes, circunstâncias históricas e tecnológicas distanciaram os falantes da Língua Portuguesa, hoje, respeitadas as respectivas culturas, aproxima-as. O mundo globalizado encurta distâncias. Pelo viés da multiculturalidade e no sentido de cultura e identidade cultural que aqui tomo (história e vivências), transitam alguns livros mais recentes. Nesse panorama, por sua miscigenação, nenhum lugar é mais propício em ambiência multicultural do que a Bahia. Desse espaço, para exemplificar o entre-lugar porposto, escolho o livro Itan dos Mais-Velhos (1996), do baiano Ruy do Carmo Póvoas, babalorixá de nome africano Catulembá. Nesse texto ficcional, além de contar histórias em formas simples, passa ensinamentos dos mais-velhos da cultura nagô, ensinamentos esses muitas vezes presentes no dia-a-dia da cidade das vivências do autor. São quatro odus, ou seja, são quatro partes que compõem o livro. Cada odu é formado por três itan. São quatro velhos que contam suas histórias. Cada um é responsável por um odu. Cada um é o narrador das suas histórias. Assim é a estrutura do livro. Eles, os velhos, não têm pressa no seu contar. "É importante retardar o final da história" diz o narrador do odu. Histórias retidas na memória, são repetidas e repetidas. É assim a tradição nagô. No livro do escritor brasileiro de etnia africana, há as presenças portuguesa, africana e brasileira. À tradição histórica africana, somam-se as 
vivências da ambiência brasileira, onde são percebidos hábitos brancos. Nesse livro, o narrador diz que "os velhos apenas sabem contar": histórias humanas, do cotidiano, não convencionais, populares. São histórias cheias de mistérios, pois "onde não há mistério, não há poder”. É um livro que exemplifica a multiculturalidade aqui mencionada, 'ponte' ficcional da lusofonia .

4 - Finalmente, não posso deixar de me referir à relação dos ficcionistas lusófonos com o oficial reconhecimento mundial da sua literatura. A estatura das três expressões - portuguesa, brasileira, africana -, há muito vem sinalizando o prêmio Nobel para um escritor de Língua Portuguesa. Refiro-me ao nosso Jorge Amado - patrimônio da Língua Portuguesa (conforme por vezes ouvi africanos e portugueses nomearem o ficcionista baiano) -, ao africano (angolano) Luandino Vieira e aos portugueses Miguel Torga e José Saramago. Afinal, em 1998, Saramago foi o ganhador do prêmio, que atraiu para a Língua Portuguesa o reconhecimento mundial da sua literatura. Destaque da Geração dos Cravos, tematizando as suas questões, José Saramago o faz de forma singular e própria. Em entrevista a Carlos Reis (JL: Lisboa, 14/10/99), falando da sua obra, ele diz: "o que há ali são livros em que eu, como cidadão, como pessoa que sou, diante do tempo, diante da morte, diante do amor, diante da idéia de Deus existente ou não, diante de coisas que são fundamentais (e continuarão a ser fundamentais), procuro colocar o conjunto de dúvidas, de inquietações e de interrogações que me acompanham". De modo geral, podemos dizer que parece haver, de uma ou outra forma, uma matafísica nos seus livros, traduzida, inclusive, na problematização da verdade e indagação do outro (presente, principalmente, em Manual de Pintura e Caligrafia, Ano da Morte de Ricardo Reis, Jangada de Pedra e Todos os Nomes). Pelo questionamento incessante dos seus personagens sobre o que buscam, Saramago chega a admitir poderem eles ser alther egos do autor. Sobre Saramago, por tudo quanto escreveu e como escreveu, a justiça do prêmio Nobel é-lhe devida e justificada. Afora a regularidade da sua produção, a maneira singular de transformar o comum em essencial, no que tange ao mais profundo, dramático e impronunciável do ser humano; a provocadora e instigante forma de repensar a história e de projetar o futuro, fazem-no merecedor do prêmio - o primeiro concedido a um escritor de Língua Portuguesa. Por isso mesmo (por ter sido concedido a um escritor de Língua Portuguesa) o prêmio é de todos os países falantes dessa Língua.

De tudo quanto disse, cabe, portanto, uma forma de entender, atentando para as diferenças culturais que envolvem os escritores de cada expressão, no que diz respeito às Literaturas de Língua Portuguesa. Se o mundo literário dos falantes de Língua

Légua of mein: Revista dr litrpatura a Diversidade Cultural -119 
Portuguesa, guardadas as respectivas expressões culturais em suas identidades, impõe-se por sua língua comum, premidos pelos tempos que exigem a comunicabilidade, a linguagem literária tem marcas que apontam para uma preocupação especial com a leveza, rapidez e visibilidade (Calvino: 1988). O olhar ficcional desloca-se para a revisão da história; em mudança de perspectiva, volta-se para as minorias sociais, para a descentralização do poder e da fala do saber, para a subjetividade do narrador. Os gêneros tomam novos ares, agora perpassados pela intertextualidade e ironia, tomados como elementos estruturais. Tais experiências temáticas e de discurso, se por um lado enriquecem as expressões de Língua Portuguesa, por outro, agudizam as discussões sobre as questões identitárias desses povos.

Por tudo quanto foi dito, a idéia é de que as travessias literárias no mundo da Língua Portuguesa, mais do que de tempo e espaço, são de interstícios. Pontos de intersecção. Entre-lugares. Fazem-se enquanto pontos diferenciadores das culturas, e se fazem enquanto presenças provocadoras de novos signos de identidade. Respeitadas as diferenças, também sinalizam uma "sociedade" supra, multicultural, de uma mesma língua flor do lácio sambódromo.

\section{SOR}

\section{REFERÊNCIAS BIBLIOGRÁFICAS}

ALEGRE, Manuel. Uma Carga de Cavalaria. Lisboa: Caminho, 1999.

ALMEIDA FARIA. A Reviravolta. Lisboa: Caminho, 1999.

ALMEIDA FARIA. O Conquistador. Lisboa: Caminho, 1990.

ALMEIDA, Germano. Dona Pura e os Camaradas de Abril. Lisboa: Caminho, 1999.

ANTUNES, A. L. As Naus. Lisboa: Dom Quixote, 1998.

ARAÚJO, J. S. O Auto do Descobrimento - o romanceiro de vagas descobertas. Ilhéus:

BARRENO, Maria Isabel. As Vésperas Esquecidas. Lisboa: Caminho, 1999.

BHABHA, H. O Local da Cultura. Belo Horizonte: Editora da UFMG, 1998.

BRITO, Carlos. Vale a Pena Ter Esperança. Lisboa: Caminho, 1999.

CALVINO, I. Seis Propostas para o Próximo Milênio: lições americanas, trad de Ivo Barroso. Caminha a El-Rei D. Manuel . Salvador: EGBa/ Editus, 1999

CARVALHO, Mário de. Apuros de um Pessimista em Fuga. Lisboa: Caminho, 1999.

COUTO, Mia. Vinte e Zinco. Lisboa: Caminho, 1999. EDITUS, 1997.

ERICKSON, F. Culture in Society and in educational practice. In: BANKS, J. A; BANKS, C. M. 
KLINDLER, A. Multiculturalismo e Formação da identidade Cultural. In: FIGUEIREDO, E. ; Lisboa: Terramar, 1998 p. 27 - 45.

PIRES, J; CALADO, N. Pedro Alvares Cabral: Ventos de Glória, Marés de Infortúnio.

PÓVOAS, Ruy do Carmo. Itan dos Mais Velhos. Salvador: BDA, 1996

RODRIGUES, Urbano Tavares. O Dia Último e o Primeiro. Lisboa: Caminho, 1999.

SALGADO, Sebastião. Um Fotógrafo em Abril. Lisboa: Caminho, 1999.

SANTOS, E (org). Recortes Transculturais. Niterói: EDUFF/ABECAN, 1997. p.13 - 25. São Paulo: Schwarcz, [1988] 1991.

SARAMAGO, J. Entrevista com Carlos Reis. JL Lisboa, 14/10/1999.

SIMÕES, H. C.; GONZAGA, R. O Achamento do Brasil- A Carta de Pero Vaz de Caminha

SIMÕES, M.L.S. As Razões do Imaginário. Salvador: FCJA/ EDITUS, 1998.

TORRES, Alexandre Pinheiro. Amor, só Amor, Tudo Amor. Lisboa: Caminho, 1999.

VIEIRA, Alice. Vinte Cinco a Sete Vezes. Lisboa: Caminho, 1999.

SIMÕES, Maria de Lourdes Netto. Travessias da literatura contemporânea de língua portuguesa. Légua \& meia: Revista de literatura e diversidade cultural. Feira de Santana: UEFS, $n^{\circ} 1$, 2002, p. 114-121.

Maria de Lourdes Netto Simões é Professora Titular da UESC. Graduada em Letras pela FAFI, Doutora pela Universidade Nova de Lisboa, Pós-Doutorada na Universidade Nova Lisboa/ Instituto Camões. Publicou artigos, ensaios e livros, dentre os quais: Caminhos da Fiçãa (1996) e As Ražões do Imaginário (1998). 


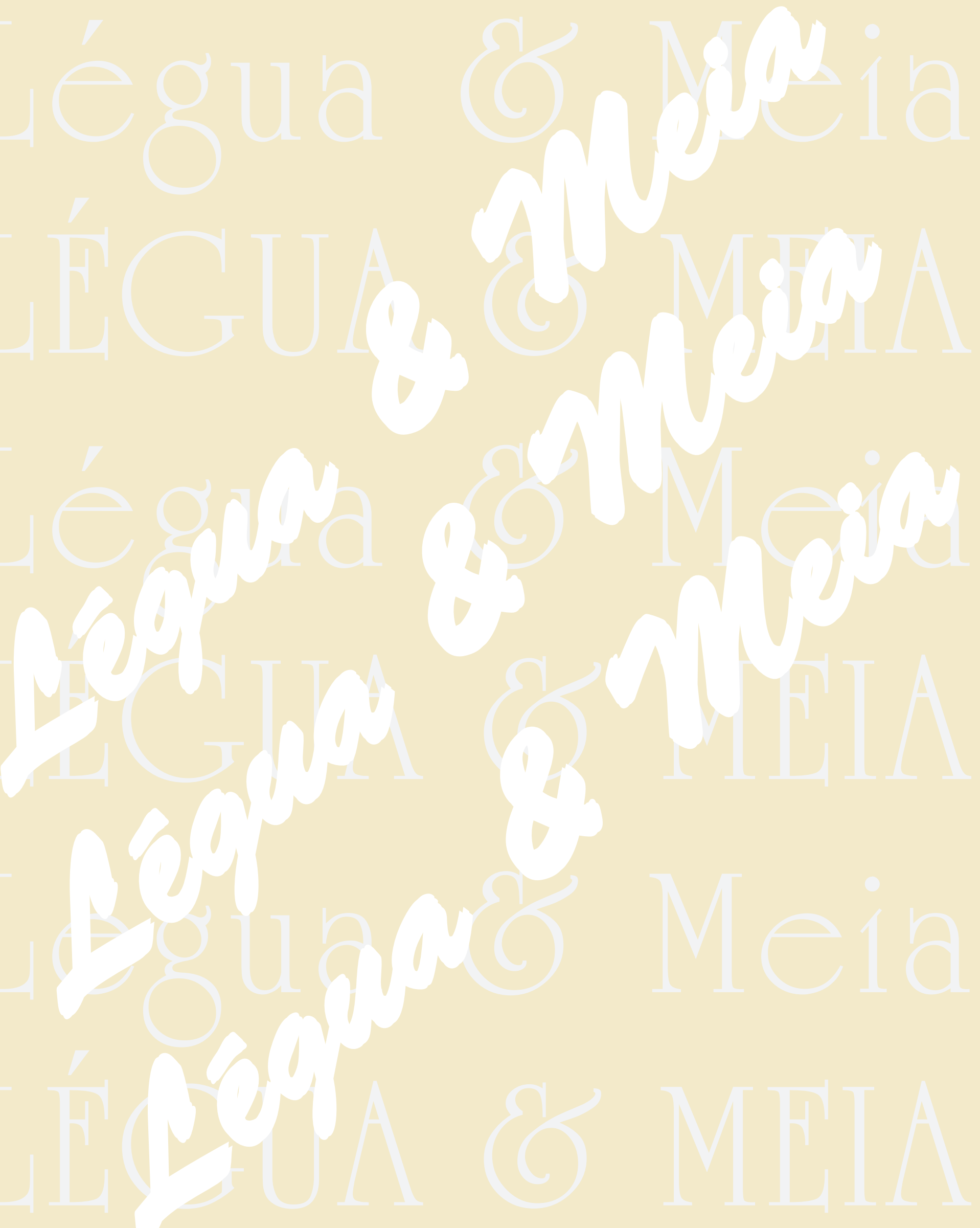

